\title{
PENGARUH KEWAJIBAN KEPEMILIKAN NPWP,PEMERIKSAAN PADAJAN DAN PENAGIHAN PAJAK TERHADAP PENERIMAAN PAJAK (Studi Kasus pada KPP Pratama Bitung)
}

\author{
Adelina Simanungkalit ${ }^{1}$ \\ Agus T. Poputra ${ }^{2}$ \\ Treesje Runtu ${ }^{3}$ \\ Jurusan Akuntansi, Fakultas Ekonomi dan Bisnis, \\ Universitas Sam Ratulangi, Manado, 95115,Indonesia

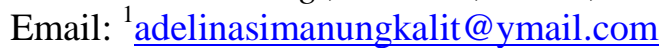

\begin{abstract}
This research aimed to analyze the influence of ownership obligations Taxpayer Identification Number, tax audit and tax collection on tax revenue. The respondents in this research were tax officer at Tax Office Bitung. Total of sample in this research are 30 person from 79 person of tax officer on Tax Office Bitung. The sampling method in this research used nonprobability sampling through purposive sampling technique. While the data processing method was used multiple regression analysis. The result showed that the obligation of ownership Taxpayer Identification Number and tax collection did not significantly affect tax revenues, while the variable of tax audit proved to have a significant positive effect on tax revenues.
\end{abstract}

Keywords: Ownership obligation Taxpayer Identification Number, tax audits, tax collection and tax revenue.

\section{Latar Belakang}

Pajak merupakan salah satu aspek yang terpenting dalam proses pembangunan suatu negara, terlebih bagi negara-negara yang sedang berkembang seperti Indonesia. Pajak secara sederhana merupakan iuran wajib yang diberikan oleh rakyat kepada negara yang telah diatur oleh pemerintah dan disesuaikan dengan peraturan perundangundangan yang berlaku serta digunakan untuk kepentingan negara demi kesejahteraan rakyat. Pemerintah mengharapkan penerimaan negara dari sektor pajak setiap tahunnya semakin meningkat mengingat bahwa pajak merupakan sumber pendapatan terbesar bagi negara Indonesia.

Untuk lebih memaksimalkan penerimaan pajak, pemerintah harus mengambil langkah-langkah kebijakan untuk memberikan pemahaman kepada masyarakat dan meningkatkan kesadaran untuk membayar pajak. Sebelum membuat kebijakan-kebijakan tersebut, ada beberapa hal yang harus diketahui oleh pemerintah sebagai pembuat kebijakan. Salah satunya adalah faktor-faktor apa saja yang mempengaruhi penerimaan pajak. Faktor-faktor yang mempengaruhi penerimaan pajak diantaranya pemerintah, petugas pajak (fiskus), dan masyarakat yang sangat berperan penting dalam upaya mengoptimalkan penerimaan pajak (Fouktone, 2007:3).

Semua wajib pajak yang telah memenuhi persyaratan subjektif dan objektif sesuai dengan ketentuan peraturan perundang-undangan perpajakan berdasarkan sistem self-assessment, wajib mendaftarkan diri pada kantor Direktorat Jenderal Pajak untuk dicatat sebagai wajib pajak dan sekaligus untuk mendapatkan Nomor Pokok Wajib Pajak (NPWP). Persyaratan objektif adalah persyaratan bagi subjek pajak yang menerima atau memperoleh penghasilan atau yang diwajibkan untuk melakukan pemotongan/pemungutan sesuai dengan ketentuan Undang-Undang Pajak Penghasilan (PPh) 1984 dan perubahannya. Wajib Pajak adalah orang pribadi atau badan, meliputi pembayar pajak, pemotong pajak dan pemungut pajak yang mempunyai hak dan kewajiban perpajakan sesuai dengan ketentuan peraturan perundang-undangan perpajakan (Casavera, 2009:4).

Selain mewajibkan masyarakat sebagai wajib pajak untuk memiliki NPWP, pemerintah juga berupaya untuk meningkatkan penegakan hukum lain sebagai pelengkap dan bentuk dukungan terhadap sistem self-assessment yang telah diterapkan karena masih banyak wajib pajak yang dengan/tanpa sengaja tidak melaporkan kewajiban perpajakannya serta kurangnya atau minimnya kesadaran perpajakan wajib pajak. Penegakan hukum ini dapat dilakukan melalui pemeriksaan dan penagihan pajak. Pemeriksaan dilakukan untuk mengetahui tingkat kepatuhan wajib pajak dalam melaksanakan kewajiban perpajakannya 
serta mencegah terjadinya penyimpangan pajak yang dilakukan oleh wajib pajak. Dengan dilakukannya pemeriksaan pajak terhadap wajib pajak, akan memberikan pengaruh yang positif terhadap peningkatan jumlah penerimaan pajak.

Selain pemeriksaan pajak, pemerintah juga melakukan penagihan pajak untuk lebih mengoptimalkan penerimaan pajak. Penagihan pajak dilakukan karena masih banyaknya wajib pajak terdaftar yang tidak melunasi hutang pajaknya sehingga diperlukan tindakan penagihan yang mempunyai kekuatan hukum yang bersifat mengikat dan memaksa. Maka dengan persetujuan Dewan Perwakilan Rakyat, pemerintah mengeluarkan UU nomor 19 tahun 2000 tentang penagihan pajak dengan Surat Paksa. Dengan dikeluarkannya undang-undang tentang penagihan pajak tersebut wajib pajak diharapkan lebih termotivasi untuk membayar tunggakan pajaknya sehingga dapat meningkatkan penerimaan pajak.

Mengacu pada uraian diatas, maka penulis tertarik untuk mengadakan penelitian dengan judul "Pengaruh Kewajiban Kepemilikan NPWP, Pemeriksaan Pajak dan Penagihan Pajak terhadap Penerimaan Pajak (studi kasus pada KPP Pratama Bitung)".

\section{Rumusan Masalah}

Berdasarkan atas beberapa hal yang telah diuraikan dalam latar belakang masalah, maka penulis merumuskan masalah yang menjadi dasar penyusunan skripsi yaitu apakah kewajiban kepemilikan Nomor Pokok Wajib Pajak (NPWP), pemeriksaan pajak dan penagihan pajak berpengaruh terhadap besarnya jumlah penerimaan pajak pada KPP Pratama Bitung.

\section{Tujuan Penelitian}

Tujuan yang ingin dicapai dalam penelitian ini adalah untuk menganalisis korelasi dan pengaruh kepemilikan Nomor Pokok Wajib Pajak (NPWP), pemeriksaan pajak dan penagihan pajak terhadap penerimaan pajak pada KPP Pratama Bitung.

\section{Tinjauan Pustaka}

Menurut Undang-Undang Ketentuan Umum dan Tata Cara Perpajakan No.28 tahun 2007 Pasal 1 ayat 1, Pajak adalah Kontribusi Wajib kepada Negara yang terutang oleh orang pribadi atau badan yang bersifat memaksa berdasarkan Undang-Undang, tidak mendapatkan imbalan secara langsung dan digunakan untuk keperluan Negara bagi sebesar-besarnya kemakmuran rakyat.

Pajak mempunyai beberapa fungsi, yaitu sebagai berikut.

1. Fungsi Penerimaan (Budgetair)

2. Fungsi Mengatur (Regulared)

3. Fungsi Stabilitas

4. Fungsi Redistribusi

5. Fungsi Demokrasi

Asas-asas dalam penerimaan pajak adalah sebagai berikut.

1. Asas Domisili (asas kependudukan)

2. Asas Sumber

3. Asas Kebangsaan

Sistem pemungutan pajak terdiri atas tiga jenis, yaitu sebagai berikut.

1. Official Assessment System

2. Self-Assessment System

3. Withholding System

Nomor Pokok Wajib Pajak menurut Waluyo (2009:24) adalah nomor yang diberikan Direktur Jenderal Pajak kepada wajib pajak sebagai sarana administrasi perpajakan yang dipergunakan sebagai tanda pengenal diri atau identitas wajib pajak dalam melaksanakan hak dan kewajiban perpajakannya.

Menurut Mardiasmo (2013:26), fungsi Nomor Pokok Wajib Pajak adalah sebagai berikut.

1. Sebagai tanda pengenal diri atau Identitas Wajib Pajak.

2. Untuk menjaga ketertiban dalam pembayaran pajak dan dalam pengawasan administrasi perpajakan.

Menurut Undang-Undang Ketentuan Umum dan Tata Cara Perpajakan No.28 tahun 2007 Pasal 1 ayat (25), disebutkan bahwa yang dimaksud dengan pemeriksaan pajak adalah serangkaian kegiatan menghimpun dan mengolah data, keterangan, dan/atau bukti yang dilaksanakan secara objektif dan professional berdasarkan suatu standar pemeriksaan untuk menguji kepatuhan pemenuhan kewajiban 
perpajakan dan/atau untuk tujuan lain dalam rangka melaksanakan ketentuan peraturan perundang-undangan perpajakan.

Tujuan dilakukannya pemeriksaan pajak adalah sebagai berikut.

1. Menguji kepatuhan pemenuhan kewajiban perpajakan Wajib Pajak dan untuk tujuan lain dalam rangka melaksanakan ketentuan peraturan perundang-undangan perpajakan.

2. Tujuan lain dalam rangka melaksanakan ketentuan peraturan perundang-undangan perpajakan.

Menurut Prastowo, Yustinus (2009:181) tahapan pemeriksaan pajak dibagi menjadi 5 (lima), yaitu sebagai berikut.

1. Tahap Persiapan

2. Pelaksanaan Pemeriksaan Pajak

3. Penyelesaian Pemeriksaan Pajak

4. Tugas Tambahan

5. Tindak Lanjut

Penagihan pajak adalah serangkaian tindakan agar Penanggung Pajak melunasi utang pajak dan biaya penagihan pajak dengan menegur atau memperingatkan, melaksanakan penagihan seketika dan sekaligus, memberitahukan Surat Paksa, mengusulkan pencegahan, melaksanakan penyitaan, melaksanakan penyanderaan, menjual barang yang disita (Pasal 1 angka 9 UU No. 19/2000).

Peran penerimaan pajak sangat penting bagi kemandirian pembangunan, karena pajak merupakan salah satu sumber penerimaan Negara dari dalam negeri yang paling utama selain dari minyak dan gas bumi untuk mendanai Anggaran Pendapatan dan Belanja Negara (APBN). Peningkatan penerimaan pajak memegang peranan strategis karena akan meningkatkan kemandirian pembiayaan pemerintah.

\section{METODE PENELITIAN}

\section{Jenis Penelitian}

Jenis penelitian yang dilakukan adalah penelitian deskriptif.

\section{Tempat dan Waktu Penelitian}

Penelitian ini dilakukan pada Kantor Pelayanan Pajak (KPP) Pratama Bitung dan waktu penelitian ini berlangsung pada bulan Juni sampai bulan Juli 2015.

\section{Populasi dan Sampel}

Populasi dalam penelitian ini adalah seluruh pegawai yang ada pada Kantor Pelayanan Pajak (KPP) Pratama Bitung yang berjumlah 79 orang. Sampel dalam penelitian ini berjumlah 30 orang pegawai KPP Pratama Bitung.

\section{Sumber Data}

Sumber data yang digunakan dalam penelitian ini terdiri atas dua sumber data, yaitu sebagai berikut (Sugiyono, 2010:137).

1. Data primer

2. Data sekunder

\section{Jenis Data}

Jenis data yang digunakan dalam penelitian ini adalah data kuantitatif. Menurut Sugiyono (2010), metode penelitian kuantitatif dapat diartikan sebagai metode penelitian yang berlandaskan pada filsafat positivisme, digunakan untuk meneliti pada populasi atau sampel tertentu, pengumpulan data menggunakan instrumen penelitian, analisis data bersifat kuantitatif/statistik, dengan tujuan untuk menguji hipotesis yang telah ditetapkan. Filsafat positivisme memandang realitas/gejala/fenomena itu dapat diklasifikasikan, relative tetap, konkrit, teramati, terukur, dan hubungan gejala bersifat sebab akibat.

\section{Teknik Pengumpulan Data}

Teknik pengumpulan data yang digunakan penulis adalah antara lain sebagai berikut.

1. Wawancara

Metode wawancara merupakan metode pengumpulan data dengan cara mengadakan tanya jawab langsung maupun diskusi dengan orang-orang yang berhubungan langsung dengan objek penelitian. 
Dalam hal ini, penulis melakukan wawancara dengan staf pembukuan perusahaan yang juga menangani perpajakan pada perusahaan.

2. Dokumentasi

Metode dokumentasi adalah metode pengumpulan data dengan mengadakan pengumpulan data dan dokumen secara langsung didalam penelitian.

\section{Metode Analisis}

\section{Regresi Linear Berganda}

Berdasarkan hubungan antara variabel kewajiban kepemilikan NPWP $\left(\mathrm{X}_{1}\right)$, pemeriksaan pajak $\left(\mathrm{X}_{2}\right)$, penagihan pajak $\left(\mathrm{X}_{3}\right)$, dan penerimaan pajak $(\mathrm{Y})$, maka model analisa regresi linear berganda adalah sebagai berikut.

$$
\mathbf{Y}=\mathbf{a}+\mathbf{b}_{1} \mathbf{X}_{1}+\mathbf{b}_{2} \mathbf{X}_{2}+\mathbf{b}_{3} \mathbf{X}_{3}+\mathbf{e}
$$

Keterangan: $\quad \mathrm{Y} \quad$ : penerimaan pajak

a : konstanta

b : koefisien regresi

$\mathrm{X}_{1} \quad$ : kewajiban kepemilikan NPWP

$\mathrm{X}_{2} \quad$ : pemeriksaan pajak

$\mathrm{X}_{3} \quad$ : penagihan pajak

e : error

\section{Uji Kualitas Data}

Uji kualitas data dapat dilakukan dengan cara berikut ini.

1. Uji Validitas Instrument

Uji validitas digunakan untuk mengukur sah atau valid tidaknya suatu kuesioner.

2. Uji Reliabilitas Instrument

Suatu kuesioner dikatakan reliable atau handal jika jawaban seseorang terhadap pertanyaan adalah konsisten atau stabil dari waktu ke waktu.

\section{Uji Asumsi Klasik}

Uji asumsi klasik dapat dilakukan dengan cara berikut ini.

1. Uji Multikolinearitas

2. Uji Heteroskedastisitas

3. Uji Normalitas

\section{Uji Hipotesis}

1. Uji Statistik F

Uji hipotesis dapat dilakukan melalui dua cara berikut ini.

Uji statistik F pada dasarnya menunjukkan apakah semua variabel independen atau bebas yang dimasukkan dalam model mempunyai pengaruh secara bersama-sama terhadap variabel dependen/terikat dan juga untuk menguji kesesuaian model.

2. Uji Statistik t

Uji hipotesis dilakukan dengan uji statistik $\mathrm{t}$ untuk menguji signifikansi koefisien regresi dengan ketentuan sebagai berikut.

$\mathrm{H}_{0}$ : Tidak terdapat pengaruh positif signifikan antara kewajiban kepemilikan NPWP, pemeriksaan pajak, dan penagihan pajak terhadap penerimaan pajak pada KPP Pratama Bitung.

$\mathrm{H}_{\mathrm{a}}$ : Terdapat pengaruh positif signifikan antara kewajiban kepemilikan NPWP, pemeriksaan pajak, dan penagihan pajak terhadap penerimaan pajak pada KPP Pratama Bitung. 


\section{Definisi Operasional dan Pengukuran Variabel}

\section{Variabel Independen}

1. Kewajiban Kepemilikan NPWP $\left(\mathrm{X}_{1}\right)$

2. Pemeriksaan Pajak $\left(\mathrm{X}_{2)}\right.$

3. Penagihan pajak $\left(\mathrm{X}_{3}\right)$

\section{Dependen}

Variabel dependen dari penelitian ini adalah penerimaan pajak (Y).

\section{HASIL PENELITIAN DAN PEMBAHASAN}

\section{Profil Kantor Pelayanan Pajak Pratama Bitung}

Kantor Pelayanan Pajak Pratama Bitung adalah salah satu kantor pelayanan pajak modern yang ada di provinsi Sulawesi Utara yang diresmikan pada tanggal 24 November tahun 2008 yang dibentuk dari gabungan kantor pelayanan pajak Manado, kantor pelayanan pajak bumi dan bangunan Manado dan kantor pelayanan pajak bumi dan bangunan Amurang serta kantor pemeriksaan pajak Manado. KPP Pratama Bitung mempunyai wilayah kerja 1 kota dan 2 kabupaten yaitu Kota Bitung, Kabupaten Minahasa, serta Kabupaten Minahasa Utara. KPP Pratama Bitung juga membawahi 1 Kantor Pelayanan Penyuluhan dan Konsultasi Perpajakan (KP2KP) Tondano yang berlokasi di Tondano yang bertugas untuk memberikan penyuluhan kepada wajib pajak dalam melakukan kewajiban perpajakannya.

Kantor Pelayanan Pajak Pratama Bitung merupakan kantor pajak baru yang didirikan dijalan Samratulangi Kota Bitung. Ketika masih dalam tahap pembangunan, pelayanan perpajakan Kantor Pelayanan Pajak Pratama Bitung dioperasikan digedung kantoe eks Kantor Pelayanan Pajak Bumi dan Bangunan yang beralamat dijalan 17 Agustus Manado.

\section{Karakteristik Responden}

\section{Deskripsi Responden Berdasarkan Jenis Kelamin}

\begin{tabular}{|c|l|c|c|}
\hline No. & \multicolumn{1}{|c|}{$\begin{array}{c}\text { Karakteristik } \\
\text { Responden }\end{array}$} & Jumlah & Persentase \\
\hline 1. & Jumlah Sampel & $\mathbf{3 0}$ & $\mathbf{1 0 0 \%}$ \\
\hline 2. & Jenis Kelamin & 18 & $60 \%$ \\
& a. Pria & 12 & $40 \%$ \\
& b. Wanita & $\mathbf{3 0}$ & $\mathbf{1 0 0 \%}$ \\
\hline 3. & Ustal & 8 & $26,7 \%$ \\
& a. 20-29 Tahun & 12 & $40 \%$ \\
& b. 30-39 & 10 & $33,3 \%$ \\
& c. > 39 Tahun & $\mathbf{3 0}$ & $\mathbf{1 0 0 \%}$ \\
\hline 4. & Total & 14 & $46,7 \%$ \\
& Pendidikan Responden & 16 & $53,3 \%$ \\
& a. D3 & $\mathbf{3 0}$ & $\mathbf{1 0 0 \%}$ \\
\hline
\end{tabular}

Sumber : Data primer yang diolah, 2015 


\section{Hasil Penelitian}

\section{Hasil Uji Regresi Linier Berganda}

Tabel 1

Hasil Uji Regresi Linier Berganda

Coefficients $^{\mathrm{a}}$

\begin{tabular}{|c|c|c|c|c|c|c|}
\hline \multirow{2}{*}{\multicolumn{2}{|c|}{ Model }} & \multicolumn{2}{|c|}{ Unstandardized Coefficients } & $\begin{array}{c}\text { Standardized } \\
\text { Coefficients }\end{array}$ & \multirow[b]{2}{*}{$\mathrm{T}$} & \multirow[b]{2}{*}{ Sig. } \\
\hline & & $\mathrm{B}$ & Std. Error & Beta & & \\
\hline 1 & (Constant) & 2.970 & 4.654 & & 638 & .529 \\
\hline & X1 & .335 & .181 & .310 & 1.846 & .076 \\
\hline & $\mathrm{X} 2$ & .380 & .181 & .367 & 2.096 & . 046 \\
\hline & $\mathrm{X} 3$ & .161 & .187 & .16 & .861 & .397 \\
\hline
\end{tabular}

a. Dependent Variable: Y

Sumber: Data primer yang diolah,2015

Hasil persamaan regresi $\mathbf{Y}=\mathbf{2 , 9 7 0}+\mathbf{0 , 3 3 5} \mathbf{X}_{\mathbf{1}}+\mathbf{0 , 3 8 0} \mathbf{X}_{\mathbf{2}}+\mathbf{0 , 1 6 1} \mathbf{X}_{\mathbf{3}}$ menggambarkan bahwa nilai konstanta sebesar 2,970 artinya kewajiban kepemilikan NPWP $\left(\mathrm{X}_{1}\right)$, pemeriksaan pajak $\left(\mathrm{X}_{2}\right)$ dan penagihan pajak $\left(\mathrm{X}_{3}\right)$ dianggap konstan sebesar 2,970.

Koefisien regresi variabel kewajiban kepemilikan NPWP $\left(\mathrm{X}_{1}\right)$ sebesar 0,335 artinya apabila kewajiban kepemilikan NPWP mengalami kenaikan $1 \%$ maka penerimaan pajak (Y) akan mengalami peningkatan sebesar 0,335 dengan asumsi nilai variabel independen lainnya tetap.

Koefisien regresi variabel pemeriksaan pajak $\left(\mathrm{X}_{2}\right)$ sebesar 0,380 artinya apabila pemeriksaan pajak mengalami kenaikan $1 \%$ maka penerimaan pajak (Y) akan mengalami peningkatan sebesar 0,380 dengan asumsi nilai variabel independen lainnya tetap.

Koefisien regresi variabel penagihan pajak $\left(\mathrm{X}_{3}\right)$ sebesar 0,161 artinya apabila penagihan pajak mengalami kenaikan $1 \%$ maka penerimaan pajak (Y) akan mengalami peningkatan sebesar 0,161 dengan asumsi nilai variabel independen lainnya tetap.

Untuk mengetahui persentase sumbangan pengaruh variabel independen secara serentak terhadap variabel dependen maka dilakukan uji koefisien determinasi $\left(\mathrm{R}^{2}\right)$. Berikut adalah tabel hasil uji koefisien determinasi.

Tabel 2

Determinasi $\left(\mathbf{R}^{2}\right)$

Model Summary ${ }^{b}$

\begin{tabular}{|l|r|r|r|r|}
\hline Model & R & R Square & Adjusted R Square & \multicolumn{2}{|c|}{$\begin{array}{c}\text { Std. Error of the } \\
\text { Estimate }\end{array}$} \\
\hline 1 & .637 & .406 & .338 & 1.638 \\
\hline
\end{tabular}

a. Predictors: (Constant), X3, X1, X2

b. Dependent Variable: Y

Sumber: Data primer yang diolah, 2015

Berdasarkan tabel model summary diatas diperoleh nilai adjusted $\mathrm{R}^{2}$ sebesar 0,338 . Hal ini menunjukkan bahwa persentase sumbangan pengaruh variabel independen (kewajiban kepemilikan NPWP, pemeriksaan pajak dan penagihan pajak) terhadap variabel dependen (penerimaan pajak) sebesar 33,8\%. Atau variasi variabel independen yang digunakan dalam model (kewajiban kepemilikan NPWP, pemeriksaan pajak dan penagihan pajak) mampu menjelaskan sebesar 33,8\% variasi variabel dependen (penerimaan pajak). Sedangkan sisanya $66,2 \%$ dipengaruhi atau dijelaskan oleh variabel lain yang tidak dimasukkan dalam penelitian ini, seperti variabel kesadaran masyarakat dan kepatuhan masyarakat. 


\section{Hasil Uji Hipotesis}

Tabel 3

Hasil Uji Statistik F

ANOVA $^{\mathrm{a}}$

\begin{tabular}{|l|r|r|r|r|r|}
\hline Model & Sum of Squares & Df & Mean Square & F & Sig. \\
\hline Regression & 47.727 & 3 & 15.909 & 5.931 & .003 \\
Residual & 69.740 & 26 & 2.682 & & \\
Total & 117.467 & 29 & & & \\
\hline
\end{tabular}

a. Dependent Variable: $\mathrm{Y}$

b. Predictors: (Constant), X3, X1, X2

Sumber: Data primer yang diolah, 2015

Berdasarkan tabel hasil uji statistik F diatas dapat diketahui bahwa nilai signifikan sebesar 0,03 lebih kecil dari nilai probabilitas $0,05(0,03<0,05)$. Hal ini berarti bahwa variabel independen yaitu kewajiban kepemilikan NPWP, pemeriksaan pajak dan penagihan pajak mempunyai pengaruh yang signifikan secara bersama-sama terhadap penerimaan pajak.

Tabel 4

Hasil Uji Statistik t Coefficients $^{\mathrm{a}}$

\begin{tabular}{|l|r|r|r|r|r|}
\hline \multirow{2}{*}{ Model } & \multicolumn{4}{|c|}{ Unstandardized Coefficients } & \multicolumn{2}{c|}{$\begin{array}{c}\text { Standardized } \\
\text { Coefficients }\end{array}$} & & \\
\cline { 2 - 4 } & \multicolumn{1}{|c|}{$\mathrm{B}$} & Std. Error & \multicolumn{1}{c|}{ Beta } & \multicolumn{1}{c|}{ T } & \multicolumn{1}{c|}{ Sig. } \\
\hline (Constant) & 2.970 & 4.654 & & .638 & .529 \\
X1 & .335 & .181 & .310 & 1.846 & .076 \\
X2 & .380 & .181 & .367 & 2.096 & .046 \\
X3 & .161 & .187 & .164 & .861 & .397 \\
\hline
\end{tabular}

a. Dependent Variable: Y

Sumber: Data primer yang diolah, 2015

Berdasarkan tabel hasil uji statistik $t$ diatas dapat diketahui bahwa nilai $t_{\text {hitung }}$ dan $t_{\text {tabel }}$ yang diperoleh dari masing-masing variabel bebas adalah sebagai berikut.

a. $\mathrm{X}_{1}$ ( kewajiban kepemilikan NPWP)

$\mathrm{t}_{\text {hitung }}=1,846, \mathrm{t}_{\text {tabel }}=2,056$, jadi $\mathrm{t}_{\text {hitung }}<\mathrm{t}_{\text {tabel. }}$. Oleh karena $\mathrm{t}_{\text {hitung }}<\mathrm{t}_{\text {tabel }}$ maka Ha $\mathrm{Ha}_{1}$ ditolak yang berarti bahwa kewajiban kepemilikan NPWP tidak berpengaruh signifikan terhadap penerimaan pajak.

b. $\mathrm{X}_{2}$ (pemeriksaan pajak)

$\mathrm{t}_{\text {hitung }}=2,096, \mathrm{t}_{\text {tabel }}=2,056$, jadi $\mathrm{t}_{\text {hitung }}>\mathrm{t}_{\text {tabel }}$. Oleh karena $\mathrm{t}_{\text {hitung }}>\mathrm{t}_{\text {tabel }}$ maka $\mathrm{Ha}_{2}$ dapat diterima yang berarti bahwa kewajiban kepemilikan NPWP berpengaruh signifikan terhadap penerimaan pajak.

c. $\mathrm{X}_{3}$ (penagihan pajak)

$\mathrm{t}_{\text {hitung }}=0,861, \mathrm{t}_{\text {tabel }}=2,056$, jadi $\mathrm{t}_{\text {hitung }}<\mathrm{t}_{\text {tabel }}$. Oleh karena $\mathrm{t}_{\text {hitung }}<\mathrm{t}_{\text {tabel }}$ maka $\mathrm{Ha}_{3}$ ditolak yang berarti bahwa penagihan pajak tidak berpengaruh signifikan terhadap penerimaan pajak.

\section{Pembahasan}

\section{Pengaruh Kewajiban Kepemilikan NPWP Terhadap Penerimaan Pajak.}

Hasil uji hipotesis 1 yang ditunjukkan pada tabel 4.15 , nilai $t_{\text {hitung }}$ pada variabel kewajiban kepemilikan NPWP $\left(\mathrm{X}_{1}\right)$ adalah 1,846 dengan tingkat signifikansi sebesar 0,076. Karena nilai $\mathrm{t}_{\text {hitung }} 1,846$ lebih kecil dari nilai $t_{\text {tabel }} 2,056$ dan nilai signifikansinya 0,076 lebih besar dari nilai probabilitas signifikan 0,05 maka $\mathrm{H}_{0}$ diterima dan $\mathrm{H}_{\mathrm{a}}$ ditolak. Dapat dikatakan bahwa kewajiban kepemilikan NPWP $\left(\mathrm{X}_{1}\right)$ tidak berpengaruh signifikan terhadap penerimaan pajak.

Sesuai dengan fumgsinya, NPWP merupakan suatu sarana administrasi perpajakan yang dipergunakan sebagai tanda pengenal diri atau identitas wajib pajak. NPWP juga digunakan untuk menjaga 
ketertiban dalam membayar pajak dan pengawasan administrasi perpajakan sehingga bagi wajib pajak yang telah memiliki NPWP diharuskan membayar pajak terhutangnya.

Namun demikian, semakin banyak masyarakat yang memiliki NPWP juga tidak menyebabkan kenaikan jumlah penerimaan pajak secara signifikan. Hal ini bisa terjadi karena disebabkan oleh beberapa faktor. Faktor pertama yang penulis kemukakan adalah kurangnya kesadaran masyarakat untuk membayar pajak. Kedua, banyak wajib pajak yang telah memiliki NPWP akan tetapi jumlah penghasilan yang diperoleh masih dibawah Penghasilan Tidak Kena Pajak (PTKP) sehingga menyebabkan tidak adanya pajak terhutang atau yang disebut juga dengan pajak nihil.

\section{Pengaruh Pemeriksaan Pajak Terhadap Penerimaan Pajak.}

Hasil uji hipotesis 2 yang ditunjukkan pada tabel 4.15 , nilai $t_{\text {hitung }}$ pada variabel pemeriksaan pajak $\left(\mathrm{X}_{2}\right)$ adalah 2,096 dengan tingkat signifikan sebesar 0.046. oleh karena nilai $t_{\text {hitung }} 2,096$ lebih besar dari nilai $t_{\text {tabel }}$ 2,056 dan nilai signifikansinya 0,046 lebih kecil dari nilai probabilitas 0,05 maka $\mathrm{H}_{0}$ ditolak dan $\mathrm{H}_{\mathrm{a}}$ diterima. Dapat dikatakan bahwa pemeriksaan pajak mempunyai pengaruh yang signifikan terhadap penerimaan pajak. Hal ini berarti bahwa semakin efektif pegawai pemeriksa pajak melakukan tahapantahapan pemeriksaan pajak terhadap wajib pajak maka akan meningkatkan jumlah penerimaan pajak secara signifikan.

Pemeriksaan pajak bertujuan untuk meredam kecurangan-kecurangan yang dilakukan oleh wajib pajak untuk memilnimalkan pajaknya. Dalam rangka pemenuhan hak dan kewajiban perpajakan wajib pajak, maka pegawai perpajakan melakukan pemeriksaan rutin terhadap wajib pajak.

Hasil penelitian ini konsisten dengan penelitian yang dilakukan oleh Marisa Heryanto dan Agus Arianto Toly (2013) yang menyatakan bahwa pemeriksaan pajak memiliki hubungan yang positif signifikan terhadap penerimaan pajak.

\section{Pengaruh Penagihan Pajak Terhadap Penerimaan Pajak.}

Hasil uji hipotesis 3 yang ditunjukkan pada tabel 4.15 nilai $t_{\text {hitung }}$ pada variabel penagihan pajak $\left(\mathrm{X}_{3}\right)$ adalah 0.861dengan tingkat signifikansi 0,397 . Oleh karena nilai $t_{\text {hitung }} 0,861$ lebih kecil dari nilai $t_{\text {tabel }} 2,056$ dan tingkat signifikansi 0,05 maka $\mathrm{H}_{0}$ diterima dan $\mathrm{H}_{\mathrm{a}}$ ditolak. Dapat dikatakan bahwa variabel penagihan pajak tidak berpengaruh signifikan terhadap penerimaan pajak.

Penagihan pajak adalah serangkaian tindakan yang dilakukan oleh pegawai perpajakan agar wajib pajak melunasi hutang pajaknya. Penagihan pajak dilakukan dengan menegur atau memperingatkan, melaksanakan penagihan seketika dan sekaligus, memberitahukan surat paksa, mengusulkan pencegahan, melaksanakan penyitaan, melaksanakan penyanderaan dan menjual barang yang telah disita. Melalui serangkaian tahapan-tahapan tersebut diharapkan dapat membuat wajib pajak segera melunasi kewajiban perpajakannya sehingga dapat meningkatkan penerimaan pajak.

Namun kurangnya tingkat kepatuhan dari wajib pajak serta kurang optimalnya kinerja dari pegawai perpajakan dalam hal ini para penagih pajak yang bertugas dalam tindakan penagihan melakukan upaya untuk membuat wajib pajak segera melunasi kewajiban perpajakannya sehingga tindakan penagihan pajak ini tidak memberikan pengaruh yang signifikan untuk meningkatkan jumlah penerimaan pajak. Para pegawai perpajakan harus bersifat aktif dalam malakukan penagihan pajak agar wajib pajak sadar dan lebih patuh terhadap peraturan perpajakan sehingga mereka segera melunasi kewajiban perpajakannya.

Hasil penelitian ini konsisten dengan penelitian yang dilakukan oleh Sony Junaidy dan Amelia Sandra yang menyatakan bahwa penerimaan pelunasan tunggakan pajak yang diperoleh tidak mencapai target karena masih sangat rendahnya kepatuhan wajib pajak untuk melunasi tunggakan pajaknya yang berarti bahwa wajib pajak baru akan melunasi tunggakan pajaknya setelah adanya penagihan aktif.

\section{PENUTUP}

\section{Kesimpulan}

Kesimpulan dari penelitian ini adalah.

1. Variabel kewajiban kepemilikan NPWP, dan penagihan pajak tidak berpengaruh secara signifikan terhadap penerimaan pajak pada KPP Pratama Bitung.

2. Variabel pemeriksaan pajak merupakan variabel yang memiliki pengaruh signifikan terhadap penerimaan pajak pada KPP Pratama Bitung. Hal ini dapat dilihat dari nilai beta penagihan pajak yang paling tinggi. 


\section{Saran}

Saran dari penelitian ini adalah.

1. Penelitian selanjutnya diharapkan dapat menambah jumlah variabel lainnya untuk mengetahui variabelvariabel lain yang dapat mempengaruhi penerimaan pajak.

2. Penelitian selanjutnya diharapkan dapat memperluas wilayah cakupan atau melibatkan lebih banyak KPP, tidak hanya satu KPP saja sehingga dapat diperoleh hasil penelitian yang tingkat generalisasinya lebih tinggi.

3. Penelitian selanjutnya diharapkan menggunakan lebih banyak sampel untuk mendapatkan hasil yang lebih akurat mengenai variabel-variabel yang mempengaruhi penerimaan pajak.

4. Untuk KPP Pratama Bitung diharapkan dapat lebih meningkatkan upaya kinerja dari para pegawainya untuk dapat memaksimalkan jumlah penerimaan pajak.

\section{DAFTAR PUSTAKA}

Casavera, 2009. Perpajakan, Cetakan Pertama. Graha Ilmu. Yogyakarta.

Fouktone, 2007. "Optimalisasi Penerimaan Pajak Melalui Pembenahan Sistem Administrasi Pajak".

Ghozali, Imam, 2011. Aplikasi Analisis Multivariate Dengan Program IBM SPSS 19, Edisi Ketiga. Badan Penerbit Universitas Diponegoro. Semarang.

Herryanto, Marisa dan Agus Arianto Toli, 2013. "Pengaruh Kesadaran Wajib Pajak, Kegiatan sosialisasi Perpajakan, dan Pemeriksaan Pajak terhadap Penerimaan Pajak Penghasilan di KPP Pratama Surabaya Sawahan" Tax and Accounting Review, Vol.1, No.1.

Junaidy dan Sandra, 2009. "Evaluasi Proses Pelaksanaan Penagihan Pajak dalam Rangka Pengamanan Penerimaan Pajak (Studi Kasus di KPP Jakarta XYZ)" Simposium Nasional Akuntansi.

Mardiasmo, 2013. Perpajakan, Edisi Revisi. Andi. Yogyakarta.

Prastoyo, Yustinus, 2009. Panduan Lengkap Pajak, Raih Asa Sukses. Jakarta.

Priyatno, Duwi, 2013. Mandiri Belajar Analisis Data Dengan SPSS. MediaKom. Yogyakarta.

Sugiyono, 2010. Metode Penelitian Kuantitatif Kualitatif dan R\&D. Alfabeta. Bandung.

Undang-Undang Nomor 28 Tahun 2007 tentang Ketentuan Umum dan Tata Cara Perpajakan.

Undang-Undang Republik Indonesia Nomor 19 Tahun 2000 tentang Perubahan atas Undang-Undang Nomor 19 Tahun 1997 tentang Penagihan Pajak dengan Surat Paksa.

Waluyo, 2009. Perpajakan Indonesia, Edisi Kedua. Salemba Empat. Jakarta. 